\title{
El cómic como lenguaje visual híbrido y su vigencia en la era digital contemporánea
}

\author{
Edward Leandro Muñoz
}

Es diseñador visual y magíster en diseño y creación interactiva de la Universidad de Caldas (Manizales, Colombia). Se ha desempeñado profesionalmente como ilustrador editorial. Es editor de la publicación de cómic Dr. Fausto Fanzine y coordinador de El Club de Lectores de Cómic del área cultural del Banco de la República de Manizales.

Fecha de recepción: 9 de abril de 2016

Fecha de aceptación definitiva: 18 de mayo de 2016 


\title{
Resumen
}

El distanciamiento del cómic con las altas esferas del arte y la academia tiene una de sus muchas raíces en el falso conflicto impuesto entre la imagen y la palabra, perpetuado a través de buena parte de la historia humana. Afortunadamente hace algunas décadas se han venido reconociendo las virtudes de los medios híbridos como el cómic para expresar distintas realidades humanas que se escapan a las aproximaciones lineales, unilaterales y monosensoriales de medios más tradicionales. Este artículo busca evidenciar cómo el lenguaje visual presente en el cómic, que mezcla interrelaciones entre palabra escrita y representación gráfica, es más vigente que nunca en un contexto contemporáneo poblado de herramientas digitales que posibilitan la mezcla de diferentes medios en manifestaciones creativas variadas. La compilación de recursos simbólicos que convergen en el cómic se muestra ahora como un fenómeno sincronizado con el devenir contemporáneo que lo ha llevado a reclamar nuevos escenarios para reafirmar su vigencia artística y su legitimidad como medio. El museo de arte, las librerías tradicionales, los salones de clase y el periodismo han sido testigos de las virtudes que atesora el cómic en esta renovada etapa de su historia.

Palabras clave: Cómic, cómic digital, historieta, lenguaje visual, webcómic

\begin{abstract}
The distancing of comics with the high spheres of art and academia has one of its many roots in the false conflict imposed between the image and the word, perpetuated throughout much of human history. Fortunately for decades, the virtues of hybrid media such as comics have been recognized to express different human realities that escape the linear, unilateral and monosensory approaches of more traditional media. This article seeks to show how the visual language present in comics, which mixes interrelations between written word and graphic representation, is more effective than ever in a contemporary context of digital tools that allow the mixing of different media in different creative manifestations. The compilation of symbolic resources that converge in comics is now shown as a phenomenon synchronized with the contemporary becoming that has led him to reclaim new scenarios to reaffirm his artistic validity and legitimacy as a medium: The art museum, traditional bookstores, Classrooms and journalism have witnessed the virtues of the comic book at this renewed stage of its history.
\end{abstract}

Keywords: Comic, Digital Comic, Comic-Book, Visual Language, Webcomic

\section{Cita bibliográfica}

Muñoz, E. L. «El cómic como lenguaje visual híbrido y su vigencia en la era digital contemporánea», en CuCo, Cuadernos de cómic n.o 8 (2017), pp. 7-30. 
La historieta no ha detenido su avance en búsqueda de legitimación. En espacios que antes estaban reservados a otros medios, el cómic ha sabido hacerse lugar, empezando por las librerías generalistas, pasando por museos, galerías, salones de clases de todos los niveles académicos hasta inclusive convertirse en objeto de interés por parte de las ciencias del lenguaje y otras áreas del conocimiento. Mientras tanto, los medios digitales e internet han mutado la manera de crear, leer, difundir y comercializar el cómic; es propósito de este artículo entender los cambios en el lenguaje simbólico al interior de las historietas que han desencadenado dichas herramientas digitales partiendo de un análisis inicial del lenguaje del cómic.

\section{Apuntes sobre el lenguaje visual del cómic y sus retos en el contexto digital}

Los símbolos que ahora conocemos como letras de los diversos alfabetos tienen su origen con la representación visual. Dice Eisner: «Las palabras están hechas de letras. Las letras son símbolos derivados de imágenes que se originaron a raíz de formas familiares, objetos, posturas y otros fenómenos reconocibles. Así, a medida que su uso se volvió más sofisticado, se fueron haciendo cada vez más esquemáticas y abstractas». ${ }^{1}$

Vale preguntarse entonces cuándo se inicia la separación de ambos (escritura e imagen) y por qué la necesidad de mantenerlos distanciados, ya que, aunque sean diferentes, nunca serán opuestos. Groensteen se pregunta respecto a este tema: «Why should two of the most respected forms of human expression, literature (the model for all narrative arts) and drawing (the foundation of all fine arts), be dethroned and debased as soon as they are side by side in a mixed media?» ${ }^{2}$

Para Neil Cohn, para empezar a clarificar se debe reflexionar acerca de cómo los cómics encajan adecuadamente dentro del objeto de estudio de las ciencias del lenguaje ya que: «Language is a human behavior while comics are not. Comics are a social object that is the result of two human behaviors: written and drawing. Believing "comics" are an object of inquiry would be akin to linguists focusing on "novels" as opposed to studying English».3

${ }_{1}^{1}$ Eisner, W. El cómic y el arte secuencial. Barcelona, Norma Editorial, 2002, p. 16.

2 Groesteen, T. «The Impossible Definition», en Heer, J.y Worcester, J. A Comics Studies Reader. Jackson, University Press of Mississippi, 2009, p. 9.

3 Cohn, N. «Comics, Linguistics and Visual language: the Past and the Future of a Field», en Bramlett, F. (ed.). Linguistics and Study of Comics. New York, Palgrave MacMillan, 2012, pp. 92-118. 
En este sentido, la lingüística debe centrarse en el lenguaje visual resultante de la mezcla entre la escritura y dibujo y no en las categorizaciones o formatos del cómic actual, esto significa, en palabras de Cohn que: «Comics themselves are not a language, but comics are written in visual languages the same way that novels or magazines are written in English. This makes comics potentially written in both a visual language and a written language». ${ }^{4}$

Así como la escritura es una manifestación del lenguaje, el dibujo y la representación visual también lo son, el cómic como combinación de ambos comportamientos humanos resulta elemental: escritura y dibujo son herramientas inseparables en la evolución natural del lenguaje. Podemos afirmar entonces que el cómic es un lenguaje visual antes que un arte. ¿Por qué entonces la resistencia histórica que se tiene contra el cómic por parte de las élites culturales y académicas?

Thierry Groensteen reflexiona sobre la actitud desaprobadora de la sociedad francesa ante los cómics en la mitad del siglo xx, en especial de los educadores, ya que para ellos los cómics atentaban contra la moral y la inteligencia de los niños y jóvenes: "Comics are seen as intrinsically bad because they tend to take the place of "real books", an attitude which crystalizes a double confrontation: between the written word and the world of images, on the one hand; between educational literature and pure entertainment on the other». ${ }^{5}$

Las historietas llevan a cabo una eficaz reconciliación entre texto e imagen y es precisamente esta relación explícita en los cómics lo que los llevó a consagrarse como producto de masas. Los historietistas tienen la capacidad de contar historias con altos grados de humor, crítica y sátira en el espacio reducido de (por ejemplo) cuatro viñetas. Primero fueron los periódicos los que se dieron cuenta de los alcances del lenguaje secuencial y de su rentabilidad y luego como industria independiente gracias al éxito de los comic-books.

Otras artes con mucha mayor tradición histórica y académica (pintura, poesía, grabado) han establecido unos límites más claros en sus lenguajes y han evolucionado en unos territorios con fronteras más estables. Tal como lo describe Groensteen: «In effect, comic art, just like cinema, which is also a hybrid genre, goes against the "ideology of purity" that has dominated the West's approach to aesthetics». ${ }^{6}$

Es difícil, entonces, para muchos considerar que los medios consagrados en su origen al entretenimiento puedan aportar culturalmente, por ello muchos sectores, sobre todo los académicos, consideran el lenguaje escrito depositado en el libro como único medio válido para la construcción y transmisión del saber humano y la creación, desconociendo la realidad actual del mundo poblado por imágenes, en donde resulta anacrónico perpetuar la hegemonía de la palabra escrita sobre estas. Se debe abogar por la conciliación de ambas

\footnotetext{
4 Idem.

${ }^{5}$ Groensteen, T. (2009) Op. cit.

${ }^{6}$ Idem.
} 
partes. Piscitelli, reflexionando sobre el estado actual de la lectura con los cambios que la contemporaneidad, hace hincapié en: «Por eso insistimos en que más que de muerte o fin, debemos hablar de reinvención de la lectura. Solo que esta vez los lectores serán cada vez más escritores y que su paleta no estará compuesta solo de texto sino también de imágenes, sonidos y objetos». ${ }^{7}$

La discusión no es si las tecnologías digitales serán parte fundamental de nuestras vidas cotidianas, sino hasta qué punto las permearán; a día de hoy no solo las usamos como herramientas de comunicación o entretenimiento, se han incrustado como dispositivos con la capacidad de alterar nuestros procesos de creación, de percepción y de aprendizaje, el lienzo digital tiene la capacidad de ser la superficie ideal para contener texto, imágenes y sonidos, lo que llevará, irremediablemente, a que las fronteras entre los diversos medios y lenguajes se contaminen unos a otros. El cómic, como medio híbrido, propone un diálogo constante entre la palabra escrita y los símbolos procedentes de la representación visual, reta al lector a pasar de un nivel de lectura visual a uno escrito, a maniobrar y a completar las escenas que se van describiendo, tal y como lo indica Charles Hatfield:

From reader's viewpoint, comics seem to be radically fragmented and unstable. I submit that this is their great strength: comic art is composed of several kinds of tension, in which various ways of reading - various interpretative options and potentialities - must be played against each other. If this is so, then comics readers must call upon different reading strategies, or interpreted schema, than they would use in their reading of conventional written text. ${ }^{8}$

Parece ser que las narrativas gráficas, como el cómic, en esta nueva era de la imagen digital tienen una renovada vigencia: ¿qué alteraciones y cambios en su lenguaje traerá este hecho?

Para Dave McKean debe haber una apertura que permita una comprensión más integral del cómic en una renovada era:

Comics are essentially: imagery (non-specific), and words (but not necessarily, and not forgetting that words are also images), arranged in a linear sequence to tell a story (non-specific, and in the digital realm, "linear" is up for grabs as well). That's all. No mention of ink and line, word balloons, etc. These things don't define comics, they are ticks and mannerisms you can use or lose, like "the fade out," "the voice over," "the jump cut" in film. ${ }^{9}$

$\mathrm{Al}$ proponernos el cómic un tipo de lectura intermedia entre la imagen y la palabra, tiene un abanico de medios creativos y temáticas para explorar indeterminado, y al converger el

7 Piscitelli, A. «La cultura de los poslectores». En Revista N (25 de abril de 2009). Disponible en: http://www. filosofitis.com.ar/2009/04/27/la-cultura-de-los-poslectores/

${ }^{8}$ Hatfield, C. «An Art of Tensions», en Heer, J. y Worcester, A Comics Studies Reader. Jackson, University Press of Mississippi, 2009, p. 132.

9 Pedler, M. «An Interview with Dave McKean». 16 de Noviembre de 2010. Bookslut. Disponible en http:// www.bookslut.com/features/2010 10 016702.php 
lenguaje del dibujo con el escrito tiene posibilidades infinitas para describir e indagar en realidades que se escapan, o que no tocarían con la misma sensibilidad otro tipo de lenguajes.

\section{La expansión estética del cómic y sus nuevos escenarios}

En este punto estamos ante un panorama inestable pero rico ante las posibilidades expresivas que puede utilizar el cómic. Al alterar (o liberarse) de los tradicionales formatos editoriales, se descubren en el horizonte diferentes recursos que brindan otras manifestaciones artísticas, diversos medios digitales e internet que pueden usarse en la producción de historietas: la animación, la realidad aumentada, pantallas táctiles, elementos interactivos, por nombrar algunos. Internet ha cambiado para siempre la industria, ya la hegemonía de las grandes editoriales está en decadencia, alrededor del mundo han surgido editoriales independientes que no están sujetas a las tradicionales dinámicas del mercado y pueden publicar artistas emergentes que se arriesgan y prueban los límites del lenguaje del cómic.

Pero esta libertad de formatos y medios debe emplearse con cautela, ya lo advertía Barbieri al hablar de los nuevos formatos de los cómics: «De este modo, aquellos ligámenes narrativos que constreñían al cómic en las formas editoriales anteriores ya no existen: la trama del cómic es libre como no lo había sido nunca. ¿Pero se trata de verdad de una ventaja?» ${ }^{10}$ Para él son más peligrosos los obstáculos y restricciones narrativas impuestas por un estilo o periodo, de las que parece imposible desprenderse, más que las normas y formatos editoriales; para él se distinguen a los buenos autores precisamente por su capacidad inventiva $\mathrm{y}$ transformadora dentro de los formatos establecidos.

Para un grupo de creadores de cómic las restricciones autoimpuestas son un camino para explorar la adaptabilidad y expresividad de las historietas, el movimiento francés $\mathrm{Ou}$ bapo $^{11}$ fundado en 1992, (descendiente directo de Oulipo, Ouvroir de Litterature Potentielle) a partir de limitaciones formales busca expandir la experiencia artística del cómic, experimentando con fronteras expresivas para liberar la mente creadora.

Además de preocuparse por la experimentación, la Oubapo también persigue el objetivo del reconocimiento del cómic como una forma artística adulta, independiente de sus influencias primarias con el humor y la fantasía. Evidencia de esto son los claros principios teóricos en los que se basan las creaciones de los autores suscritos a este movimiento, como lo indica Ann Miller:

Much of the remainder of Oubapo I is taken up by an article by Thierry Groensteen, which lays down the theoretical foundations for Oubapo by listing, and in most cases exemplifying,

${ }_{10}$ Barbieri, D. Los lenguajes del cómic. Barcelona, Editorial Paidós, 1993, p. 210.

11 Oubapo (Ouvroir de Bande Dessinee Potentielle) traducido vagamente al español como «Taller para el potencial del cómic» nace como un experimento para probar los límites de la práctica de la historieta. 
different types of generative and transformative constraints that have been, or could be, the basis of Oubapo exercises. This classification became an organizing principle for subsequent Oubapo work. ${ }^{12}$

El reclamo principal que hace la Oubapo de demostrar la potencialidad del cómic como un arte moderno lo logra recurriendo a la máxima recursividad simbólica posible, explotando la bidimensionalidad inherente de la página (FIG.1). La innovación en este sentido se genera al enfrentar los juegos simbólicos presentes entre texto e imagen, tensión que se plantea en la página y se resuelve a través de la participación activa del lector.

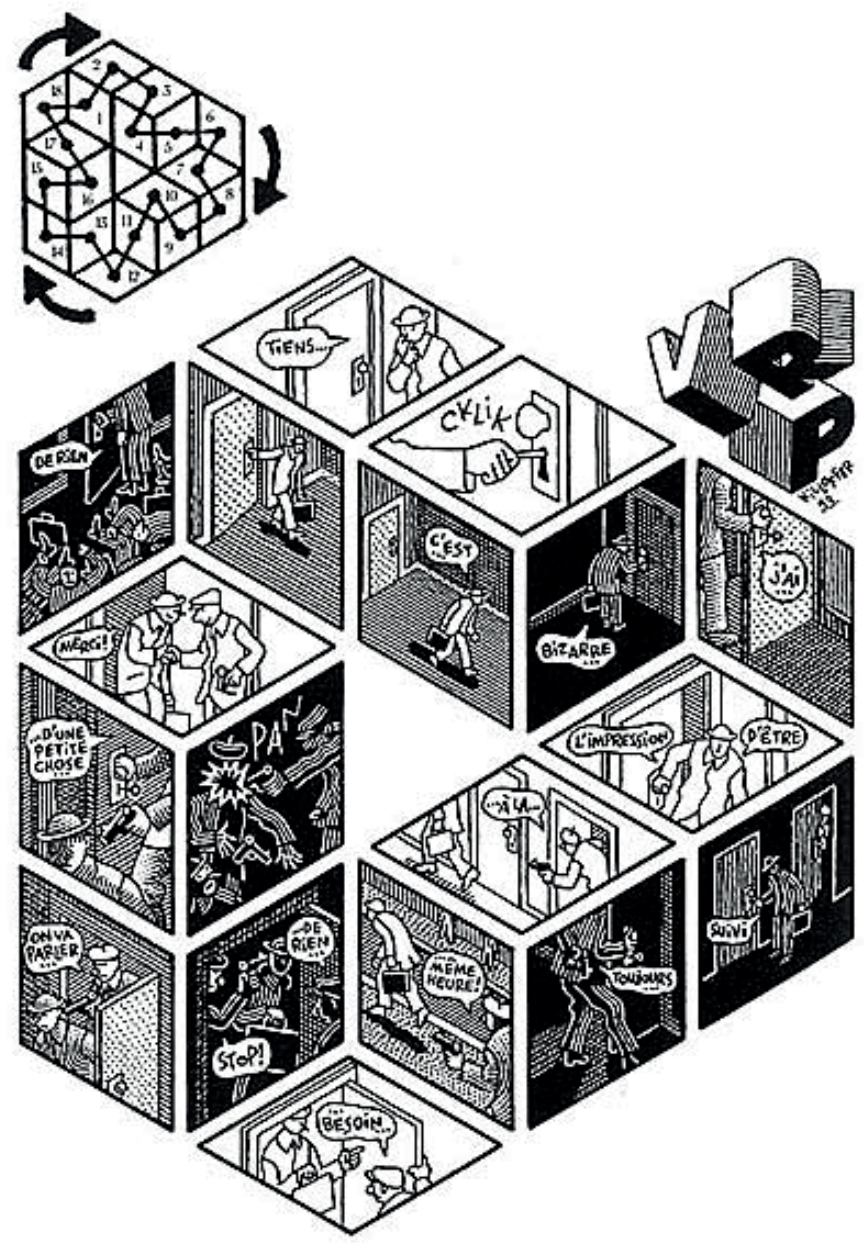

FIG. 1 Patrice Killoffer (1993) publicada en OuBapo 1 (1997). A través de la bidimensionalidad de la página Killoffer plantea un espacio ilusorio tridimensional, al rotar el formato en tres direcciones diferentes la página ofrece varias lecturas.

${ }^{12}$ Miller, A. «Oubapo: a verbal/visual medium is subject to constraints», en Word E Image: A Journal of Verbal/Visual Enquiry. Vol. 23, n. ${ }^{\circ} 2$ (2007), p. 118. 
Es válido entonces preguntarnos si la innovación y la posible mutación del cómic se encuentran al interior de su mismo lenguaje, si sus propias estrategias simbólicas son suficientes para extender las fronteras creativas o si el futuro de esta forma artística se halla en su mezcla con otros medios y lenguajes.

Más allá de los discursos apocalípticos que predecían la desaparición de los formatos impresos más bien hemos sido testigos de su transformación; Alessandro Ludovico expone, según él, una de las razones del porqué a lo largo de la historia moderna se ha predicho tantas veces la muerte de la publicación impresa y sin embargo aún se mantiene con igual vigencia:

Historically, the unchangeable, static nature of the printed medium has always been the main justification for declaring it to be obsolete. Paradoxically, it is this very immutability of paper which is now increasingly proving to be an advantage rather than a weakness, particularly in the context of an ever-changing (thus ephemeral) digital publishing world. ${ }^{13}$

Aún estamos tratando de comprender los límites y la mejor forma de cómo el papel y el pixel pueden convivir en el mundo contemporáneo, conciliando lo mejor de ambos mundos; mientras tanto, las prácticas de creación continúan y escritores, dibujantes, animadores, programadores, innovadores se unen para desarrollar productos como: $e$-books, blogs, aplicaciones de hipertexto, apps, plataformas colaborativas de creación, que se nutren tanto de las tradiciones artísticas, los formatos tradicionales y de la vanguardia tecnológica.

No debe resultar ya novedad para nadie que a medida que nos adentramos más en el siglo xxi la cantidad de información que recibimos a través de las imágenes aumenta exponencialmente, las generaciones más recientes tienen un contacto más temprano y natural con las tecnologías digitales, hecho que solo tenderá a aumentar en los próximos años. Vale entonces preguntarse acerca de la vigencia de la educación tradicional basada en la enseñanza alfanumérica para la transmisión de conocimientos procedentes de las ciencias y las humanidades, que tienden a dejar al margen la formación artística y creativa fundamental para generar competencias en resolución de problemas creativos y proyectuales, donde la modelación de soluciones a través de un lenguaje visual es esencial. El diseño de esquemas visuales y el manejo de los recursos necesarios para su realización resultan competencias fundamentales en un mundo donde el hacer y el crear han desplazado a la observación pasiva.

Por supuesto, la enseñanza del lenguaje matemático y escrito para la comprensión y desarrollo de las ciencias y las humanidades continúa siendo imprescindible para la comprensión del mundo y sus fenómenos, pero las competencias necesarias para proyectar el mundo que se desea construir recae en otra área del conocimiento humano que tiene que ver con la capacidad de crear objetos, narrativas, experiencias, servicios, espacios, entre otros, que impacten directamente sobre la conciencia material del mundo. Para Archer, esta área del conocimiento es el Diseño y su lenguaje es el modelado:

${ }_{13}$ Ludovico, A. Post Digital Print: The Mutation of Publishing since 1894. Eindhoven, Onomatopee 77, 2012, p. 9. 
The essential language of Science is notation, especially mathematical notation. The essential language of the Humanities is natural language, especially written language. The essential language of Design is modelling. A model is a representation of something [...] the vocabulary and syntax of the modeling of ideas in the Design area can be conveyed through a variety of media such as drawings, diagrams, physical representations, gestures [....$^{14}$

$\mathrm{Al}$ ser un modelo la representación de algo, este modelo se puede materializar y expresar en variedad de formas visuales (dibujo, pintura, esquemas, diagramas, mapas, objetos) y toda representación para ser comprendida posee un orden interno, una consciencia sobre la cual fue construida y que es explícita (en mayor o menor medida) para su comunicación, el cómic en este sentido posee unos recursos simbólicos que sirven para construir sofisticadas representaciones de la realidad.

Por ello se hace cada vez más necesaria una alfabetización visual (complementaria a la educación tradicional) para comprender con más profundidad el mundo en que nos encontramos, que no se compone solamente de fenómenos comprensibles a través de la notación científica y el lenguaje escrito; por el contrario, posee otras realidades cuya expresión resulta mucho más asimilable a través de construcciones visuales.

La capacidad divulgativa del cómic resulta muy atrayente en un cambio de paradigma que sitúa a la imagen al mismo nivel de la palabra y busca el diálogo entre ambos; en este sentido, Jorge Carrión habla acerca de distintas obras (cómics, ensayos gráficos) que encuentran en esta comunión un tipo de pensamiento visual difícil de enmarcar: «de pronto, el gran archivo de procedimientos explicativos y hermenéuticos que atesora el cómic se revela como un repertorio muy útil para estudiar y para expresar el mundo». ${ }^{15}$ Entre estos autores interesados en revelar las herramientas expresivas que aglutina el cómic se encuentra Nick Sousanis, autor e investigador de cómic que a través de su tesis doctoral Unflattening (desarrollada en formato de cómic) explora las relaciones que existen entre las diversas formas de conocer el mundo con los recursos cognitivos que ha desarrollado la humanidad para poder hacerlo, por medio de un diálogo entre diversas áreas del conocimiento como el lenguaje, la óptica, la biología y la astronomía, entre otros, Sousanis explica el funcionamiento de la constante necesidad por conocer el mundo recurriendo a una expansión de los sentidos y puntos de vista, argumenta que los fenómenos no tienen una única vía ni medio en la que se manifiestan por lo que el ser humano debe estar preparado en una variedad de lenguajes para comprender esas fuentes de información: «The medium we think in defines what we can see»; ${ }^{16}$ por ello resulta fundamental aceptar el hecho de que lo visual, textual y cinético componen de forma integral nuestro pensamiento.

${ }_{14}$ Archer, B. «The Three Rs», en A framework for Design Education Research Group, Department of Design and Technology. Loughborough, University and DATA, United Kingdom, 2005, p. 12.

15 Carrión,J. «Pensar con Viñetas», en El País, 14 de Abril de 2016. Disponible en http://cultura.elpais.com/ cultura/2016/04/14/actualidad/1460643514 402434.html

16 Sousanis, N. Unflattening. Cambridge, Harvard University Press, 2016, p. 52. 
En el centro del argumento de Sousanis se haya el cómic, como medio y lenguaje visual que a partir de la colisión e interacción simultánea entre texto e imagen se asemeja a la manera no lineal y compleja en la que se organiza el pensamiento humano. Aunque el uso de cualquier lenguaje siempre traerá una pérdida al intentar traducir la vasta experiencia humana en códigos tangibles, al combinar texto e imagen se crean estructuras capaces de contener mucho más significado, para Sousanis: «The verbal marches along linearly, step by step, a discrete sequence of words [...] the visual, on the other hand presents itself all-at-once, simultaneous, all over, relational [...] while the image $i s$, text is always about». ${ }^{17}$

Las construcciones lineales tienen sus ventajas comunicativas, pero no son la única vía de acceder ni comunicar el mundo, cuando aceptamos el hecho de que este se presenta simultáneamente ante nosotros y que además se relaciona con otros componentes y estructuras, dejamos de ser observadores pasivos y nos emancipamos de estructuras cognitivas rígidas. El cómic esencialmente reconoce esta realidad, en su estructura visual cohabitan tanto las reglas lineales del texto escrito junto con la espacialidad, yuxtaposición y discontinuidad de la imagen. Afirma Sousanis: «comics can hold the unflat ways in which thought unfolds» ${ }^{18}$ (FIG. 2). Así como ocurre en las historietas donde forma y contenido se unen para expresar significado en apariencia fragmentado, el pensamiento se forma a través de una multiplicidad de aproximaciones para constituir la experiencia. La mirada de Sousanis, como hemos visto, es transversal, abarca no solo al cómic como forma de expresión artística, sino que también plantea sus bondades como medio capaz de contribuir a la alfabetización visual, poniendo en manifiesto los beneficios de desarrollar un pensamiento influenciado por muchos tipos de conocimientos y experiencias, entre ellas, la visual en convergencia con la textual.

El autor de cómic contemporáneo no es un individuo encerrado en un estudio de dibujo todo el tiempo, sumergido en un universo ficticio y sometido a estructuras editoriales jerárquicas con plazos agobiantes por cumplir como era hace cincuenta años. Sus posibilidades creativas son libres como nunca antes y sus intereses artísticos van más allá del medio impreso del cómic, sus inquietudes atraviesan todo un panorama de medios y recursos, y en muchos casos las narrativas gráficas secuenciales son solo una parte de su propuesta artística.

La escultura, el vídeo, la instalación, entre otras, complementan y se integran con las historietas. Esta postura es respaldada por Jean-Christophe Menu, miembro del colectivo editorial francés L'Association y de Oubapo, quien ha sido un autor que ha abogado por la experimentación en el cómic y que ha desarrollado historietas automáticas influenciado por las posturas del surrealismo, actualmente defiende «la extrapolación de los cómics en espacios de tres dimensiones»; ${ }^{19}$ esto es, trasladar las inquietudes que trata la historieta y

17 Ibid., p. 58.

18 Ibid., p. 66.

${ }_{19}$ Menu, J. La bande dessinée et son double. Langage et marges de la bande dessinée: perspectives pratiques, théoriques et editoriales. París, l'Association, 2011, p. 496. 

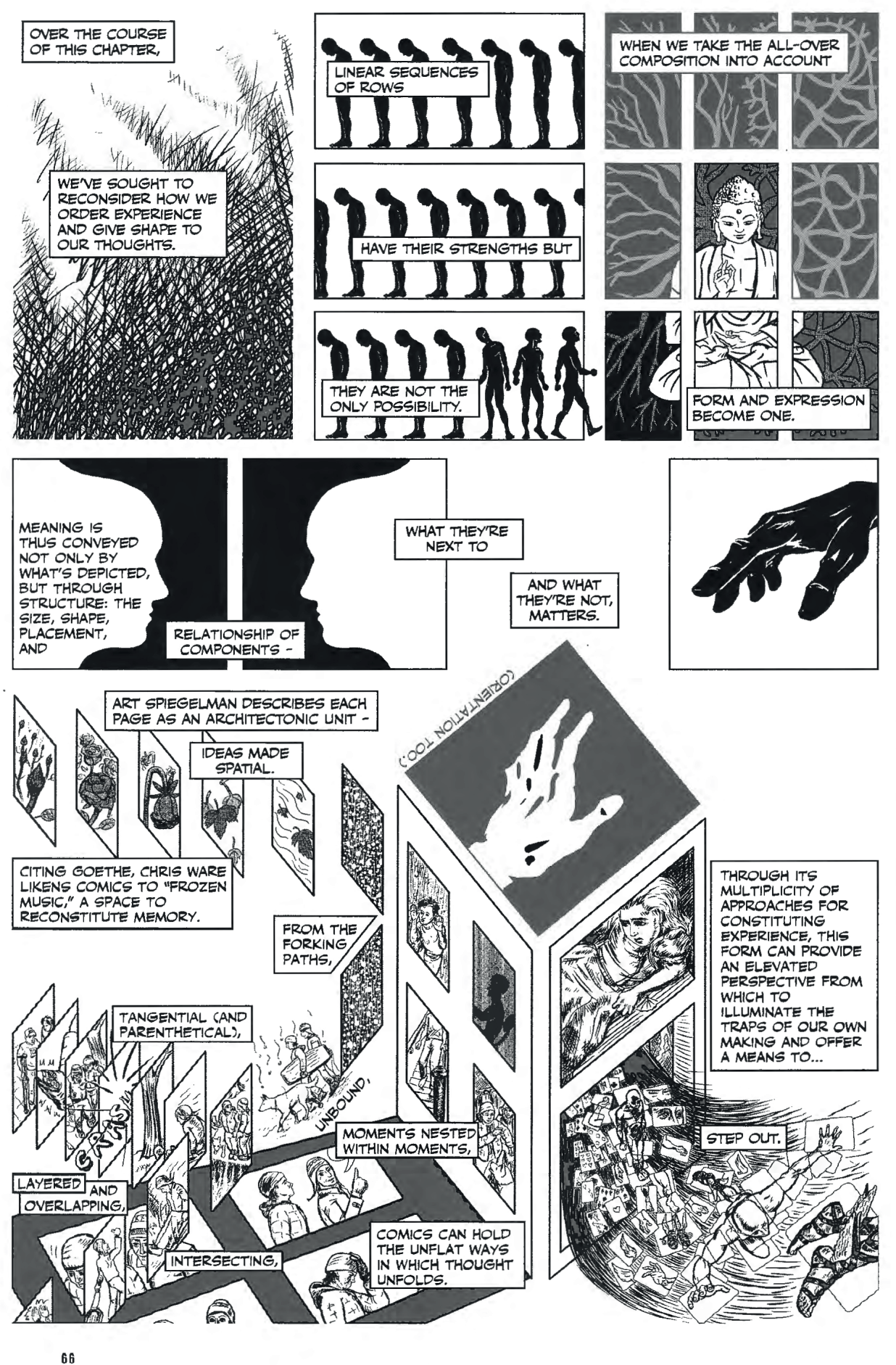

FIG. 2. Sousanis, N. Unflattening. Cambridge, Harvard University Press, 2016, p. 66. 
reflejarlas en espacios físicos superando los límites de la página impresa como lo hace Martín Vitaliti, artista argentino que mediante la deconstrucción, el collage y la instalación (FIG. 3) desarrolla una obra que reflexiona sobre el lenguaje del cómic a partir de las propias historietas. Usando páginas de comic-books, algunas veces rompiéndolas y rearmándolas, otras interviniéndolas mediante la sustracción de las viñetas y dejando solo el gutter y uno o varios personajes, logra tridimensionalizar, lo que propone la representación gráfica en un ejercicio de apropiación tanto material como simbólica en el que surgen preguntas acerca del metalenguaje del cómic.

«Utiliza la viñeta de papel como material escultórico para articular su propuesta estética y construir su muy personal lectura sobre la crisis del objeto artístico», ${ }^{20}$ afirma Varillas en una mirada sobre la obra del argentino, en este sentido la viñeta rompe su condición estática y se transforma ya no en contenedora de símbolos gráficos fijos sino que se des-aplana permitiéndole estar en el mismo plano con otros objetos físicos.

Vitaliti a través de su obra concretiza la intencionalidad de la historieta de sintetizar en símbolos la experiencia sensorial humana. Dice el artista que «la potencialidad del cómic se puede exteriorizar en un espacio físico», y esta es una de las características de su obra.

La estrategia de Vitaliti es revelar las virtudes del cómic a partir de un juego paradójico que enfrenta la representación y sus modos de visibilizarse. Así sintetiza Segade el trabajo de Vitaliti: «Su artimaña rebela una esperanza que es al mismo tiempo una rebelión en el seno del lenguaje: la constatación de que el medio, como forma de comunicación, es el mensaje pero no como razón tecnológica sino como demostración del poder que contiene en sí misma la representación». ${ }^{21}$

El cómic, su andamiaje lingüístico y sus recursos han estado rodeados por los bordes de la página impresa, pero no es ese su único contenedor, la bidimensionalidad es solo una contingencia dada por las tecnologías disponibles en el momento del surgimiento del cómic moderno; el manejo simbólico-textual, espacio-temporal y la capacidad de contener la simultaneidad de la experiencia sensorial existen más allá del formato impreso. Para intentar comprender estos fenómenos donde el cómic parece sobrepasar sus límites expresivos podemos retomar las posturas teóricas de Daniele Barbieri en su texto Los lenguajes del cómic (1993), en el cual propone el estudio del lenguaje de las historietas a partir de las relaciones que comparte con otros lenguajes como el de la pintura, la música, el cine, entre otros. Para él: «los lenguajes no son solo instrumentos que nos sirven para comunicarnos, son sobre todo ambientes en los que vivimos». ${ }^{22}$ Esto significa ver y estudiar los lenguajes como eco-

${ }^{20}$ VARILlas, R. «Martín Vitaliti y la viñeta como objeto artístico», en Catálogo de la exposición En el fondo, nada ha cambiado... Museo ABC, 2013. Disponible en http://www.martinvitaliti.net/index.php?/textos/ ruben-varillas/

${ }^{21}$ Segade, M. «Textos que ocurren», en Catálogo de la exposición Generación 2013, Proyectos de arte Caja, Madrid, 2013. Disponible en http://www.martinvitaliti.net/index.php?/textos/manuel-segade/

22 Barbieri, D. Op. cit., p. 10. 
sistemas que se relacionan unos con otros y comparten reglas comunes, pero también se distancian en ciertas características. Y como ambientes están sujetos a cambios, se adaptan con el tiempo y se transforman eventualmente, pero no arbitrariamente, solo en conciliación con los otros habitantes de dicho ecosistema.

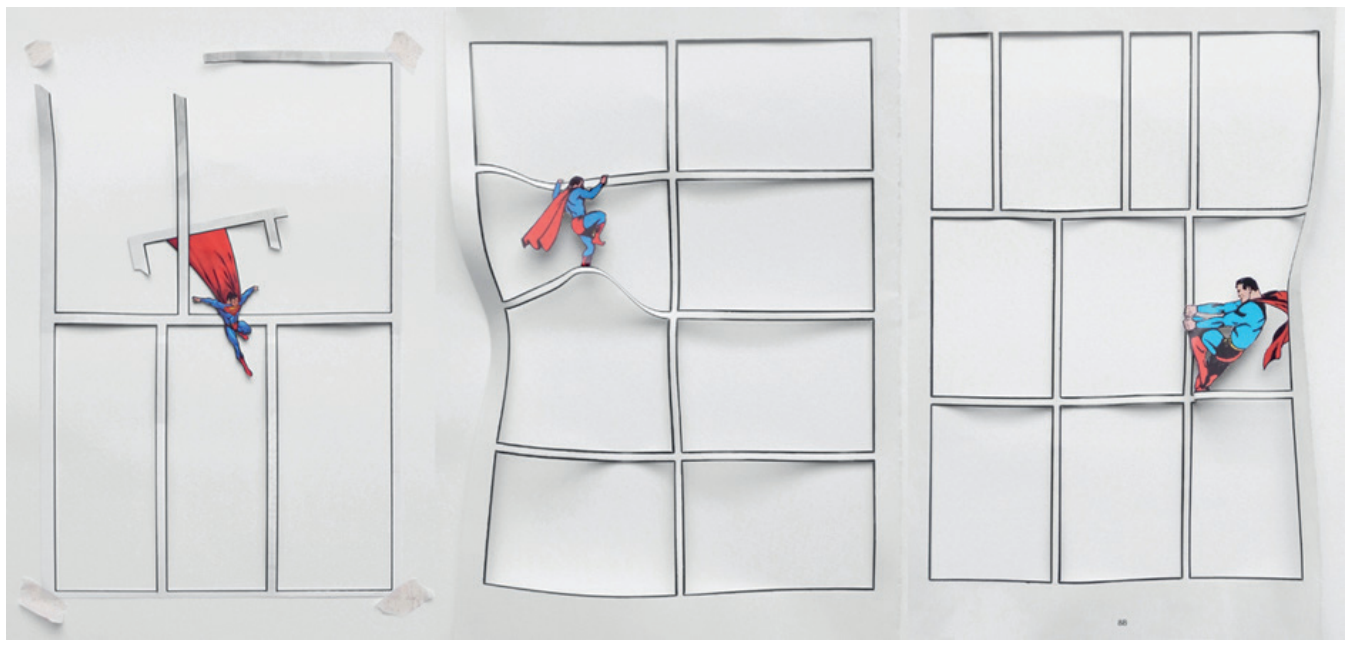

FIG. 3. A.Obra: \#21/I. Martín Vitaliti (2011).

Páginas intervenidas a partir de la publicación SUPERMAN: las primeras 100 historietas n. ${ }^{\circ}$, DC Comics / El Clarín (2010). A partir de la sustracción de las viñetas y dejando solo sus marcos, el personaje de Superman es libre de sus constreñimientos gráficos y altera materialmente las viñetas, trasladándose al universo tridimensional.

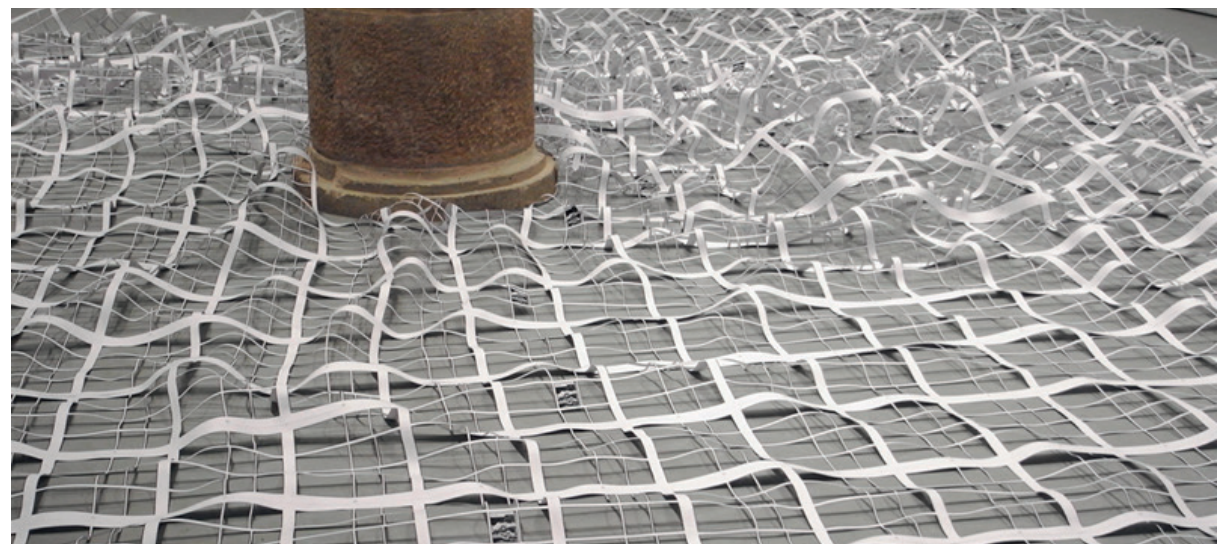

FIG. 3. B. Instalación realizada a partir de la repetición de una página de la publicación: FALK, L. y BArry, S. Phantom Daily strips. Norma Editorial, Barcelona, 1980. Dejando solo una viñeta de la página, el artista traslada la intención gráfica original del dibujante de representar una tormenta y lo lleva a un escenario real, en esta ocasión en una instalación. 


\section{El cómic digital, el webcómic y los retos en su consolidación}

Barbieri, en su texto, no menciona las relaciones del cómic con el lenguaje digital; sin embargo, podemos intentar analizar esos puntos de encuentro y distanciamiento que nos ayuden a comprender cómo dos lenguajes aparentemente tan lejanos llegan a aproximarse.

Es indiscutible que los dispositivos digitales basados en pantalla (celulares, tablets, monitores) son artefactos en los que los usuarios actuales realizan gran parte de su consumo cultural, una creciente variedad de contenidos cuentan con una versión digital: libros, revistas, periódicos, películas, series y, por supuesto, cómics. El caso más común que se da en las historietas cuando hablamos de sus versiones digitales consiste en simplemente una copia de la publicación original de papel que ha sido llevada sin alteraciones de contenido a un formato electrónico para su distribución a través de web. Las páginas siguen la secuencia original del libro o la revista impresa y no proponen ninguna novedad al lector más allá del cambio de dispositivo. Sin embargo, al ser un formato adaptable a diferentes tamaños de pantalla la integridad espacial y calidad de la experiencia de lectura se pueden ver afectadas en comparación a su versión impresa; sobre esto, Groensteen opina: «The web publishing of a comic originally intended to be read on the printed page can, then, prove to be inadequate and damaging to the format of the work by forcing it to fit into a frame of arbitrary size and shape that bears no relation to its original proportions». ${ }^{23}$

A pesar de esto, ventajas como lo son la inmediatez, costos y distribución han llevado a este tipo de cómics digitalizados (más que digitales) a tener una gran popularidad en un segmento de lectores no necesariamente formados en lectura de historieta tradicional; internet ha facilitado que este tipo de cómics se compartan y distribuyan más deprisa y a lugares y audiencias donde el cómic impreso no llegaría; sin embargo, este cambio de plataforma no propone rupturas simbólicas importantes para robustecer la práctica artística de la historieta. En este sentido Groensteen recalca: «None of the factors actually enhances or enriches the work itself. For the informed reader attached to the linguistic and aesthetic properties of comics, a sense of depletion and deterioration must logically be uppermost». ${ }^{24}$

Este tipo de cómics digitalizados ha adoptado la web como plataforma de difusión más que como herramienta de exploración artística y estética.

Pero la convergencia entre el lenguaje digital y el cómic no se agota acá: debemos considerar aquellos cómics concebidos no pensando en el medio impreso sino en el digital, para los cuales son una premisa fundamental las posibilidades interactivas y multimediales que las herramientas digitales y la web aportan.

Para un medio como el cómic, que representa el tiempo a través del espacio, gracias a la sucesión de momentos estáticos en viñetas, añadir elementos como el movimiento y el

${ }^{23}$ Groensteen, T. Comics and Narration. Jackson, University Press of Mississippi, 2013, p. 76.

24 Idem. 
sonido que no representan sino que más bien recrean el tiempo (ya que tienen duraciones específicas) supone un reto, ya que el ritmo de lectura en las historietas es impuesto por el lector, él es el responsable del tiempo; incluir animación o sonido puede suponer una ruptura en la inmersión de lectura. Por sí mismo, el cómic es en esencia multimedial al mezclar imagen y texto, creer que al añadirle más elementos se enriquece su lenguaje es afirmar que la historieta se encuentra en desventaja ante otros medios más completos. El autor de cómic digital tiene un reto: crear historias que sean lo suficientemente atrayentes para que al sumar los atributos del soporte digital no se rompa la sensación de inmersión. El buen criterio es fundamental para ser conscientes de lo necesario y diferenciarlo de lo decorativo que es tan común en una época de posibilidades técnicas y visuales como la actual.

Debemos preguntarnos por la experiencia que el cómic brinda a los lectores y las posibilidades reales que abren los medios digitales, como indica Groensteen citando a Pierre Fresnault-Derulles: «Print-medium comics are polysemiotic, in that they bring together text and image, but monosensory, calling upon sight only. Comics designed for digital media can benefit from a wider semiotic range - they are plurisensory once they involve sound, and they can, in addition, be interactive». ${ }^{25}$

La interactividad en los cómics no es novedad: el formato libro ha demostrado ser un objeto que invita al lector a su manipulación y exploración física, variadas alteraciones sobre el papel y el libro en sí mismo (como troqueles, cortes, dobleces) han permitido la expansión de la página impresa otorgando múltiples lecturas; sin embargo, la interacción digital ofrece otro nivel de manipulación sobre el contenido, como lo son los desplazamientos y rotaciones que permiten que el contenido se adapte a cambios en la dimensión de la pantalla o los acercamientos a determinados elementos gráficos que no serían posibles en la página impresa; sin embargo, lo más destacado que aporta el elemento interactivo en el cómic digital es la posibilidad de desarrollar narrativas no lineales. Groensteen las define como plurilineales, ${ }^{26}$ cuyos trayectos son planeados por el autor pero elegidos por el usuario, cada posible ruta lleva al lector a transitar por líneas narrativas que se abren como las raíces de un árbol retando el tradicional recorrido de lectura que va de un punto de inicio fijo a otro final.

Otra aproximación es la de McCloud y lo que él define como lienzo infinito: un cómic sin restricciones espaciales, que se manifiesta simultáneamente, que se extiende en todas direcciones y que es posible desarrollar gracias al formato digital, el usuario es libre de desplazarse en él, visualmente y narrativamente se expande rizomáticamente, sin rutas fijas o jerarquías predeterminadas.

Ambas visiones proponen una ruptura con el concepto tradicional de organización de página (denominada layout) que el autor logra a través del rompimiento de la narrativa (breakdown) en bloques de lectura. El desarrollo de esta metodología de creación tradicional

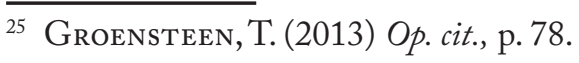

${ }^{26}$ Ibid., p. 82. 
del cómic se posicionó gracias a la coyuntura tecnológica introducida por el avance de las técnicas de impresión cada vez más sofisticadas que estandarizaron la página física como unidad en la práctica artística de la historieta, así como lo plantea Wilde: «The interruption of the continuous flow of reading and the necessity to turn a page can be understood as a technical condition brought on by print or it can be conceptualized as a design principle». ${ }^{27}$

El cómic digital es consciente de la interfaz que hereda y las virtudes de la página para desarrollar composiciones visuales y narrativas funcionales, y la adopta como una opción de diseño que ha probado su eficacia comunicativa; sin embargo, al no existir un formato físico, también es libre de romper con esta tradición. En los desarrollos de la historieta digital las estructuras visuales (viñetas, ilustraciones, textos) se desmaterializan, abandonan su formato fijo y adquieren características propias del lenguaje digital como la interacción entre ellas mismas y con el usuario, se dinamizan y responden a variables como el tamaño de la panta1la, los niveles de interacción y su capacidad de adaptación a diferentes líneas narrativas. E1 usuario toma un papel de lector e interactor activo al no solo preguntarse cómo continuará la historia sino qué más gestos deberá hacer con el dispositivo para continuar.

Groensteen tiene sus reparos acerca de este modelo de lector-interactor, ya que cree que la experiencia de lectura se deteriora al ceder protagonismo a la performatividad: «Half reader, half agent, is an unstable state that is not necessarily pleasurable, and the constant "disconnects" that interrupt the activity of reading not only create a "distancing effect" from it, they can actually prove fatal to it». ${ }^{28}$

Son comunes las reservas existentes que se tienen hacia el cómic digital, su novedad y su acercamiento a otros medios como lo son los videojuegos o la animación resultan molestos para muchos que creen defender una pureza del cómic impreso, olvidando precisamente que una de las características principales de la historieta es su hibridación con otros lenguajes; sus choques e encuentros a lo largo de la historia con la caricatura, las artes gráficas, la literatura, el cine, entre otros, es lo que nos permite disfrutar actualmente de un amplio espectro de lecturas dibujadas. Los creadores más avanzados no se detienen a preguntarse si sus motivaciones o herramientas encajan con las definiciones aceptadas en su ámbito expresivo, sus prácticas artísticas no se limitan a las consideraciones estandarizadas del medio sino que lo expanden. Precisamente el cómic digital presenta retos conceptuales que molestan pero la teoría en todos los ámbitos artísticos siempre estará relegada a las prácticas, más aún en el cómic, un medio que adolece de reflexión crítica.

La generación más joven prácticamente desde su nacimiento ha tenido contacto con dispositivos digitales y la conexión permanente a internet es ya una constante en gran parte del mundo. Los webcómics entienden esta nueva generación de lectores que busca contenidos siempre disponibles, novedosos, constantemente actualizados y fáciles de compartir gene-

${ }^{27}$ WiLde, L. «Distinguishing Mediality: The Problem of Identifying Forms and Features of Digital Comics», en Networking Knowledge: Journal of the MeCCSA Postgraduate Network, 8 (4) (2015), p. 7.

${ }^{28}$ Groensteen, T. (2013) Op. cit., p. 84. 
rando comunidades. Los webcómics abandonan la página impresa y su nueva estructura espacial es la pantalla, el dibujo en muchas ocasiones es directamente digital distanciándose de los medios análogos tradicionales para su elaboración. A pesar de estos cambios de formato y herramientas las estructuras simbólicas para su construcción y lectura continúan ligadas al cómic impreso, el lenguaje visual presente en las imágenes secuenciales es transversal a los formatos y las estructuras cognitivas necesarias para leer una novela gráfica o entender un webcómic son iguales.

En este acelerado proceso de consumo de contenidos digitales es constante la mezcla de referencias culturales, alteración de las obras al ser apropiadas por la comunidad de internet, plagios, anonimato y remezclas, fenómenos de los que no escapan los webcómics como obras de internet y para internet. La estabilidad del papel contra lo efímero del píxel genera una contradicción estética entre el cómic impreso y el webcómic, mientras las historietas editadas en comic-book o novela gráfica son publicadas con cierta conciencia de su vigencia en el tiempo, los webcómics por lo general aprovechan coyunturas sociales o identifican tendencias entre sus lectores para generar contenidos, lo que conlleva una viralización rápida en redes sociales (FIG. 4).
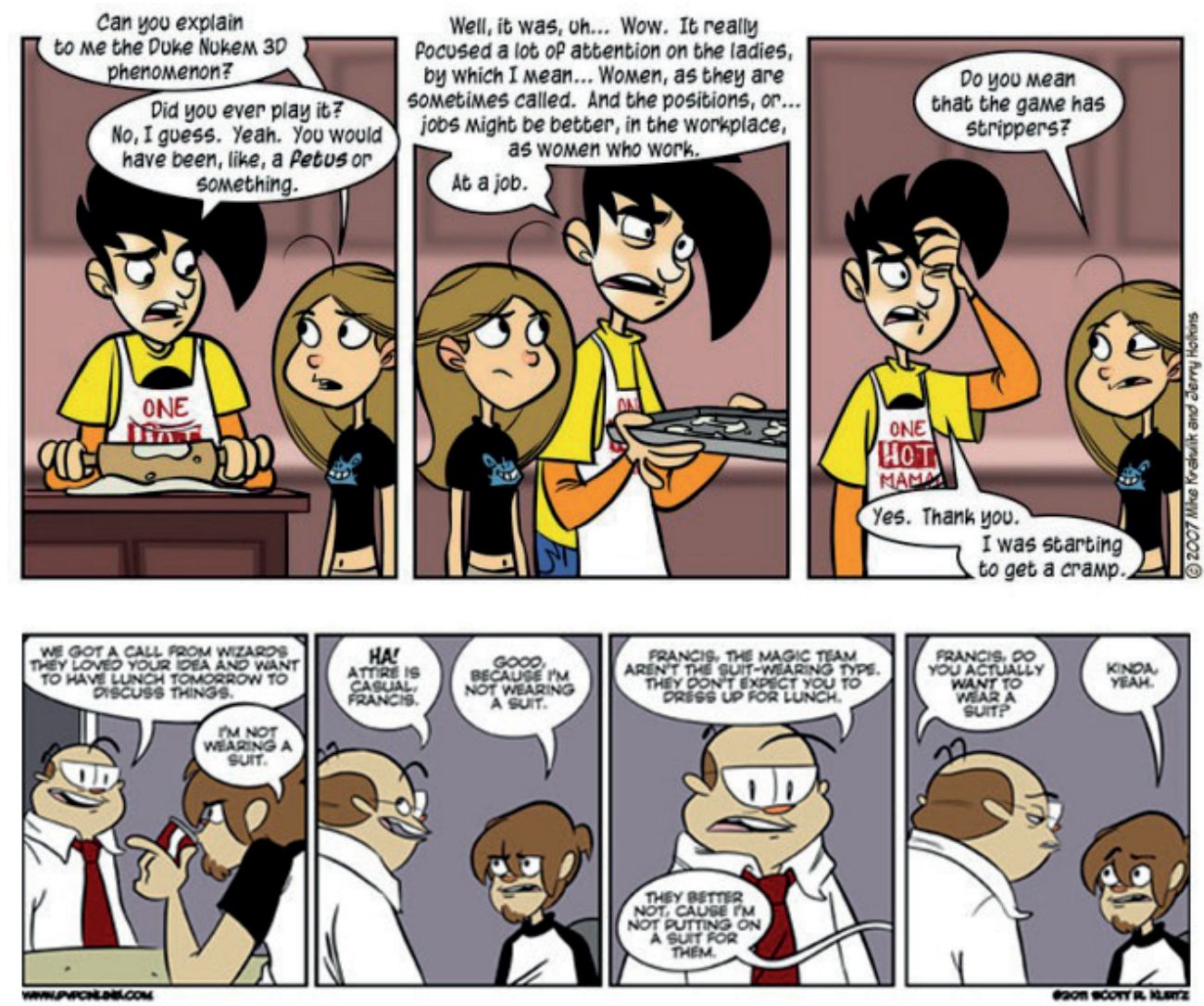

FIG. 4. (Arriba) Una tira de Penny Arcade (2001).

(Abajo) Una tira de PvP (2011). A pesar de ser webcómics, usan el modelo de serialización de principios del siglo $\mathrm{xx}$ de las tiras de prensa. 
Visualmente los webcómics pueden adquirir varias formas, siendo la más común la tira o comic-strip, compuesta por tres o cuatro viñetas, que cuenta una pequeña historia que hace parte de una narrativa mucho más extensa y prolongada en el tiempo, y es publicada con periodicidad fija, un modelo igual a las clásicas tiras de prensa pero al estar en formato digital y ser distribuida online los autores tienen completo control sobre su monetización, público y temáticas. Otras manifestaciones del webcómic son las que se inclinan más a la experimentación formal y exploran los atributos del soporte digital integrando sonido, animaciones y funciones interactivas acercándose a lo denominado como Motion Comics. [Ver Broken Saints (2001) y Nawlz (2007)]. Sobre estas manifestaciones que integran elementos multimedia, Bukatman se cuestiona:

If movement and sound are clearly different «modes» - in terms of their spatiotemporal and sensorial reception, as well as in terms of semiotics - how could they be treated as comics? Since sound and movement are both time-based phenomena, they seem to contradict comics' conception of space as representation of time - the 'conceptual fundament of the medium. ${ }^{29}$

Las contradicciones conceptuales que genera el cómic en soporte digital se pueden sintetizar, por un lado, en su tendencia a imitar los formatos tradicionales del cómic impreso, hecho que no tiene sentido al ser un medio diferente lleno de nuevas posibilidades, y, por otra parte, cuando se aventura a proponer otras formas de lectura e interacción con el lector se escapa de los límites estandarizados del cómic y empieza a rozar los bordes de la animación y las experiencias multimedia, lo que para muchos resulta molesto. McCloud en este punto afirma:

Muchos en la profesión usan el ordenador solo como una herramienta para llevar a cabo de manera más eficaz tareas que ya se hacían en los años en los que las separaciones de color las llevaba a cabo un equipo de viejas señoras de Bridgeport armadas con lancetas. Este conservadurismo es un pequeño ejemplo de la extendida tendencia que tenemos a interpretar los nuevos medios con los filtros de los viejos. [...] Por lo tanto, no es de sorprender que la sensibilidad derivada del arte lineal y la reproducción mecánica dominará los primeros días de los cómics generados por ordenador [...]. Pero usar los ordenadores como herramienta básica para nuestro arte es como acceder a una paleta de opciones casi sobrehumanas, y limitarse a imitar a sus predecesores es como cazar conejos con un portaaviones. ${ }^{30}$

Es fácil dejarse asombrar por lo vistoso de las técnicas digitales, sobre todo en un medio como el cómic donde su apartado gráfico y narrativo ha estado supeditado a lo fijo del formato impreso. Cuando se presentan los recursos técnicos que posibilitan expandir la obra de cómic de naturaleza estática hacia los terrenos dinámicos e interactivos de las creaciones digitales es de esperar que esto genere una corriente de creadores y obras explorando dichas virtudes, hasta el punto del desgaste sobre las mismas prácticas; sin embargo, hay otras formas de asumir lo digital no solamente como un cúmulo de tecnologías y técnicas novedosas

${ }_{29}$ Bukatman, S. «Online Comics and the Reframing of the Moving Image», en Harries, D. (ed.). The Nerw Media Book. London, BFI Publishing, 2011, p. 134.

${ }^{30}$ McCloud, S. La Revolución de los Cómics. Barcelona, Norma Editorial, 2001, p. 45. 
que son apropiadas y dominadas rápidamente para generar tendencias sino como una nueva era y mentalidad caracterizada por la velocidad de la información, la facilidad del acceso al conocimiento, la generación de comunidades de creación en torno a temáticas específicas pero que paradójicamente acentúan lo efímero sobre lo permanente, la desconexión humana y el distanciamiento en las relaciones, la técnica sobre la ética y el consumo sobre la conservación de recursos. Ante la aparente apertura, libertad y empoderamiento que nos brindan los medios digitales es valiosa una postura reflexiva y crítica al respecto y más si se usa el mismo lenguaje digital como forma de resistencia; por ello las prácticas creativas del cómic digital deben madurar en su propuesta estética.

Como he planteado, el cómic digital debe avanzar formalmente hacia la generación de conceptos más sofisticados que se desliguen del uso ornamental de la multimedia y reflexionen sobre su propio medio, ya no estático, fijo e impreso sino dinámico, modificable e inmaterial (FIG.5) rescatando características de la tradición del cómic, como su ingenio para construir narrativas, su capacidad para conectarse con el lector y su mirada reflexiva y satírica hacia la sociedad.

Para ejemplificar este planteamiento recurro a un par de obras que a mi modo de ver representan esa superación de las técnicas multimedia como ornamento y recurren a conceptos de la cultura digital como es el remix y la apropiación cultural. En el webcómic This

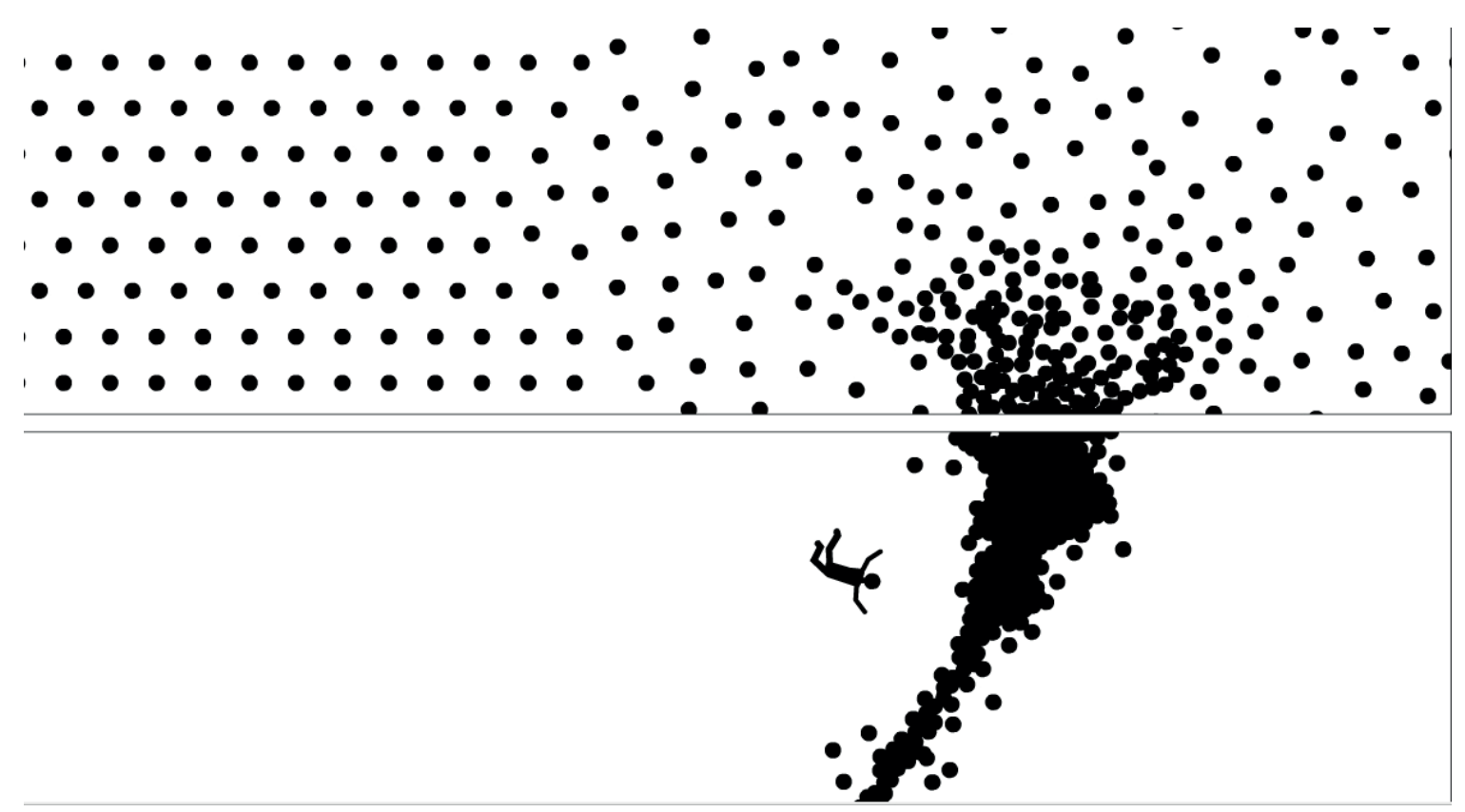

FIG. 5. Prise De Tête (2009) Disponible en http:// www.prisedetete.net/ Cómic interactivo que a través de un ingenioso y sencillo planteamiento resulta refrescante en comparación a Motion comics que pretende sorprender desde su apartado técnico vistoso. Sin embargo, por más sobrios que sean los niveles de interacción sigue habiendo un rompimiento de la experiencia de lectura. 
Charming Charlie (FIG. 6) la clásica tira Peanuts creada por Charles Schulz es alterada para que los diálogos de sus personajes sean letras de las canciones de la banda de rock The Smiths; para los fanáticos de la tira o de la banda, o de ambos, la mezcla resulta divertida o hasta adecuada, ya que las personalidades de los personajes y de las letras tienen un tono nostálgico y depresivo que encaja, para el lector desprevenido la mezcla pasa desapercibida, ya que se puede leer la tira como si esta fuera su construcción original, planteando un reflexión acerca de la capacidad de la mente humana de deducir significado a pesar de una narrativa gráfica con alteraciones. Un caso similar es el de Garfield Minus Garfield (FIG. 7), en donde las viñetas de la tira son modificadas borrando el clásico personaje de Garfield, dejando solo a Jon en una conversación consigo mismo, generando en el lector una sensación de extrañeza, de vacío, sentimiento con que el lector se puede identificar.
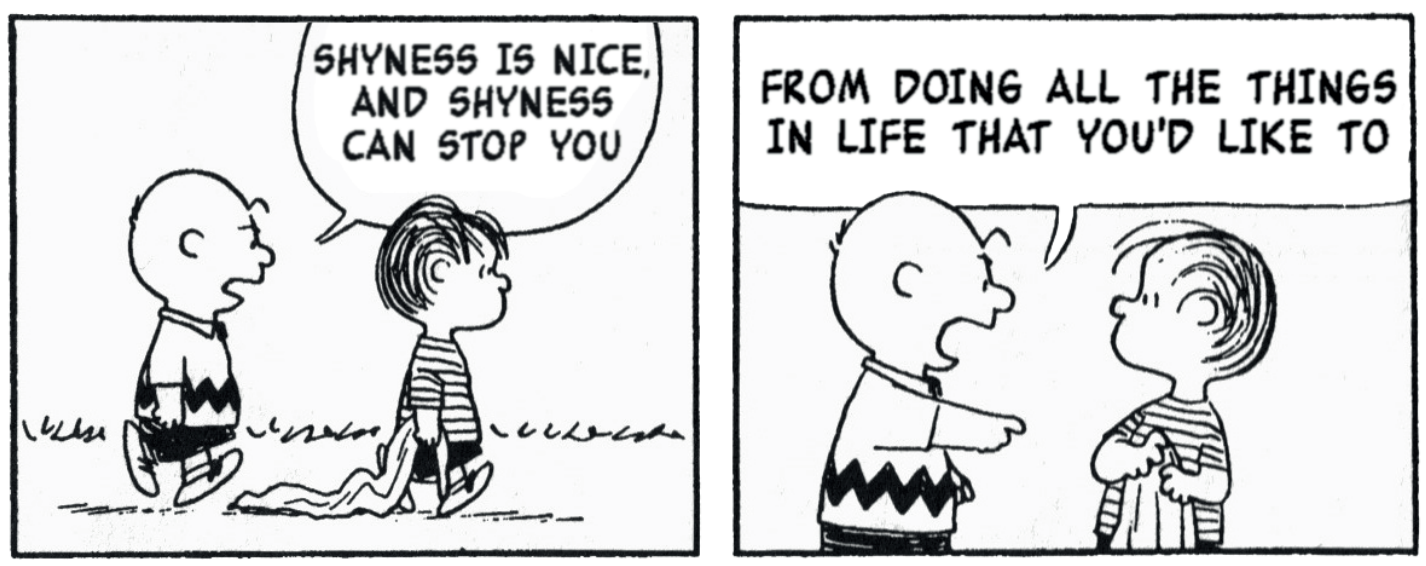

FIG. 6. This Charming Charlie. Disponible en

http://thischarmingcharlie.tumblr.com/
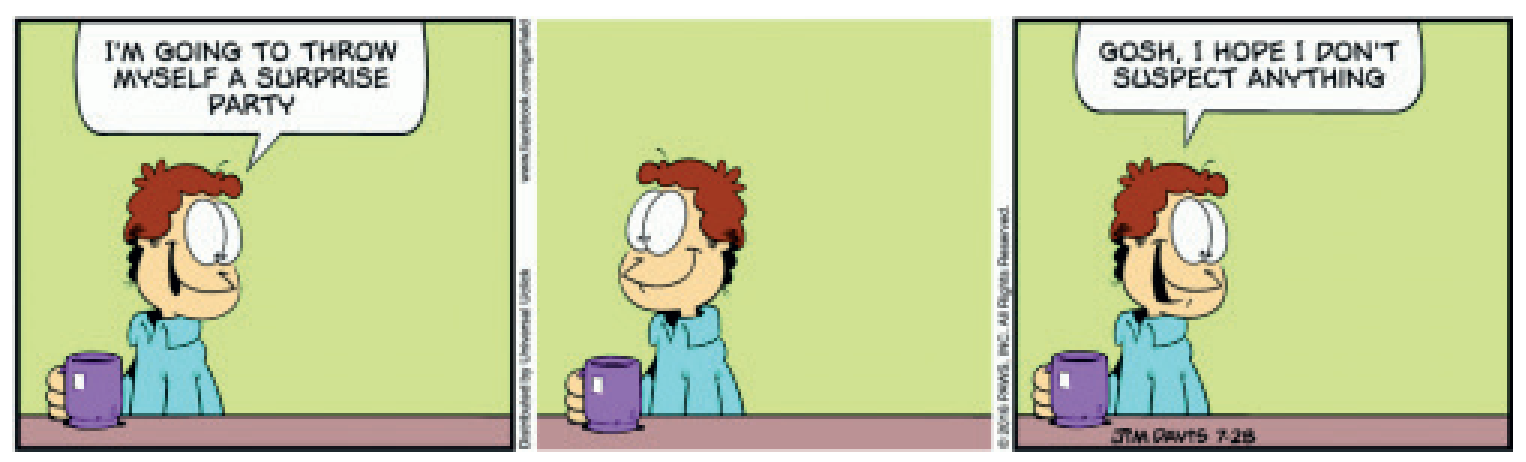

FIG. 7. Garfield Minus Garfield. Disponible en http://garfieldminusgarfield.net/

Pero el cómic digital no se debe agotar en los límites de la pantalla: esto supondría una mutilación de las capacidades de los medios digitales para proponer diálogos con los espacios físicos y sus habitantes.

En la instalación interactiva de Nova Jiang Ideogenetic Machine (FIG. 8), fotografías de los participantes son capturadas en tiempo real y luego manipuladas por un software que las 


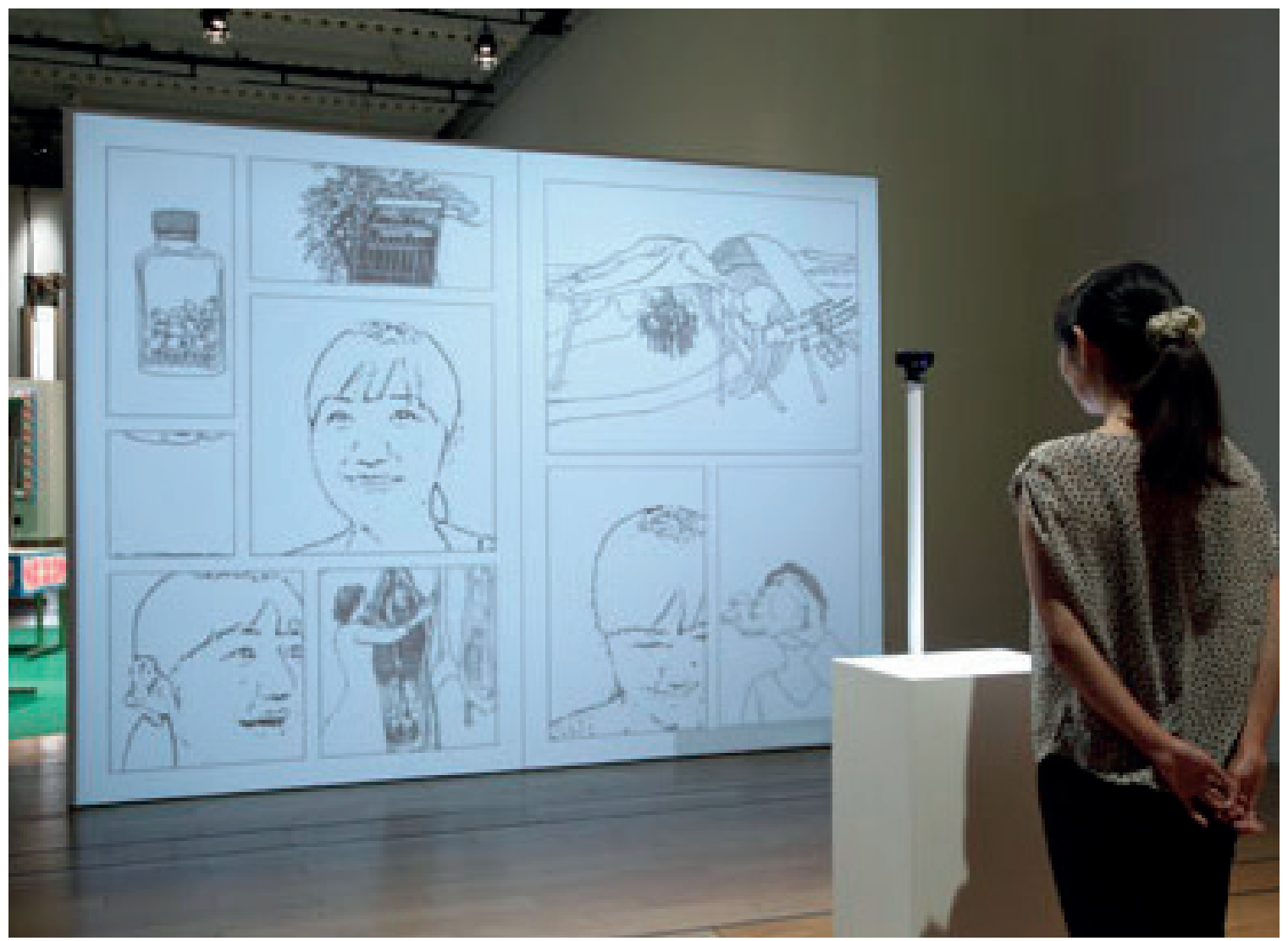

FIG. 8. Fotografía del montaje de la instalación Ideogenetic Machine (2013) por Nova Jiang. Registro de la instalación: https://vimeo. $\underline{\mathrm{com} / 30341877}$

edita en un estilo blanco y negro de alto contraste y las proyecta junto con otras ilustraciones provenientes de una base de datos; las viñetas y la organización espacial en que se disponen en la proyección son generadas por un algoritmo. Los participantes se convierten en protagonistas de una página de cómic generada espontáneamente. En esta propuesta se entremezclan conceptos derivados de las artes electrónicas como la interactividad, obra abierta, arte generativo, creación en tiempo real, participación y co-creación junto con una estética visual proveniente de las narrativas gráficas: yuxtaposición de imágenes estáticas, composición de página e ilustraciones delimitadas por viñetas, lo que genera ciertas inquietudes: ¿puede un software generar una narrativa gráfica a partir de imágenes provenientes de una base de datos y de fotografías tomadas en tiempo real? ¿La narrativa es algo deliberado que surge de la intencionalidad de un autor o es el lector quien le da sentido a una serie de imágenes aleatorias a partir de su observación? Siempre se ha entendido al cómic como un arte espacial y material, ¿̇ también puede ser temporal y efímero? ¿ $\mathrm{O}$ esta instalación es simplemente una provocación que usa elementos del lenguaje del cómic para confundirnos? Precisamente este tipo de preguntas son las que se deben generar cuando los recursos visuales del cómic son usados en el contexto del arte digital para generar reflexiones acerca de la naturaleza del lenguaje visual. 
Aunque esta instalación no es cómic, así como la columna de Trajano y el tapiz de Bayeux tampoco lo son, sí pertenecen a un tipo de creación que integra símbolos visuales con una intención narrativa en un contexto específico. Lo interesante de confrontar este tipo de creaciones con los cómics es observar que sin importar la época o el soporte artístico o material tienen elementos comunes, como el uso de símbolos específicos de un lenguaje, la doble articulación entre símbolos visuales que obligan al espectador a interpretar una porción del espacio gráfico en relación con el todo y aprovechan la capacidad de la percepción humana de rellenar los vacíos y deducir una intención narrativa.

Internet y los procesos de apropiación digital lograron consolidar las prácticas creativas del cómic en soporte digital cuyas características principales son la capacidad de incluir más sentidos en la experiencia lectora y la posibilidad de expandir las narrativas a través de estructuras no lineales. No es más adecuado que otros soportes, no representa el fin del cómic impreso ni tampoco un punto de partida, es un nuevo modo de asumir la creación secuencial gráfica, una que es más consciente de su pertenencia a un contexto digital contemporáneo más que a una tradición narrativa, por ello sus influencias son más cercanas a prácticas de internet como el blogging, la gamificación, la viralización o el remix, y es gracias a la coyuntura de su aparición que podemos plantear reflexiones acerca de la materialidad del cómic impreso versus la medialidad del cómic digital, discusión que aporta a la reflexión sobre la naturaleza de la historieta, su estética y sus alcances, evidenciando una vez más la capacidad adaptativa del cómic a los cambios y soportes que van surgiendo a través de la historia.

\section{Conclusiones}

Los cambios que ha sufrido el cómic a lo largo de las décadas no han sido fortuitos; por el contrario, una serie de condiciones culturales, económicas, tecnológicas y sociales los han propiciado, y han hecho de la historieta un medio que ha sabido adaptarse a circunstancias externas que han alterado su propio lenguaje. Las transiciones que permitieron a las historietas pasar gradual y lentamente del periódico a la revista, luego al libro y posteriormente a la web y al museo de arte no surgieron solo por los cambios de la industria o el avance de los soportes tecnológicos, sino que ha existido una evolución en el interior de su estructura simbólica, que se ha dado gracias, por ejemplo, a movimientos emancipadores como el cómic underground, que han ayudado al medio a tomar conciencia de sí mismo y plantearse como un arte maduro, crítico y digno de ser sometido a reflexiones serias.

Una de las tendencias que vemos ahora es la necesidad de retar la tradicional página bidimensional que ha tomado más de un siglo en ser explorada y comprendida para expandirla hacia otros planos físicos o tridimensionales como plantea Jean-Christophe Menu y que materializan artistas como Martín Vitaliti. Sin embargo, existen autores que continúan encontrando posibilidades inexploradas de la página impresa, como Richard McGuire y su obra Here (1989) (FIG. 9), Chris Ware con Building Stories (2012) (FIG. 10), Patrick Killoffer y muchos otros historietistas actuales. 
Es indudable la capacidad de las herramientas digitales de ofrecer un amplio abanico de recursos visuales, textuales, sonoros e interactivos para la creación, aprendizaje y enseñanza, herramientas que deben ser usadas para expandir los modos de pensar y conocer el mundo. Estas herramientas emancipan la creación humana de formatos y soportes establecidos y de categorías de creación artística (cómic, literatura, pintura, teatro, audiovisual) que tal vez en un futuro tiendan a fusionarse, mutar, expandirse o extinguirse; sin embargo, teniendo en cuenta estas posibilidades técnicas es muy necesaria una sofisticación simbólica del cómic digital para que su estética no se estanque entre la ambigüedad del cómic impreso y las experiencias multimedia. Uno de sus retos es saber diferenciar si proponer una lectura inmersiva o una experiencia sensorial, ya que ambas categorías pueden entrar en conflicto.
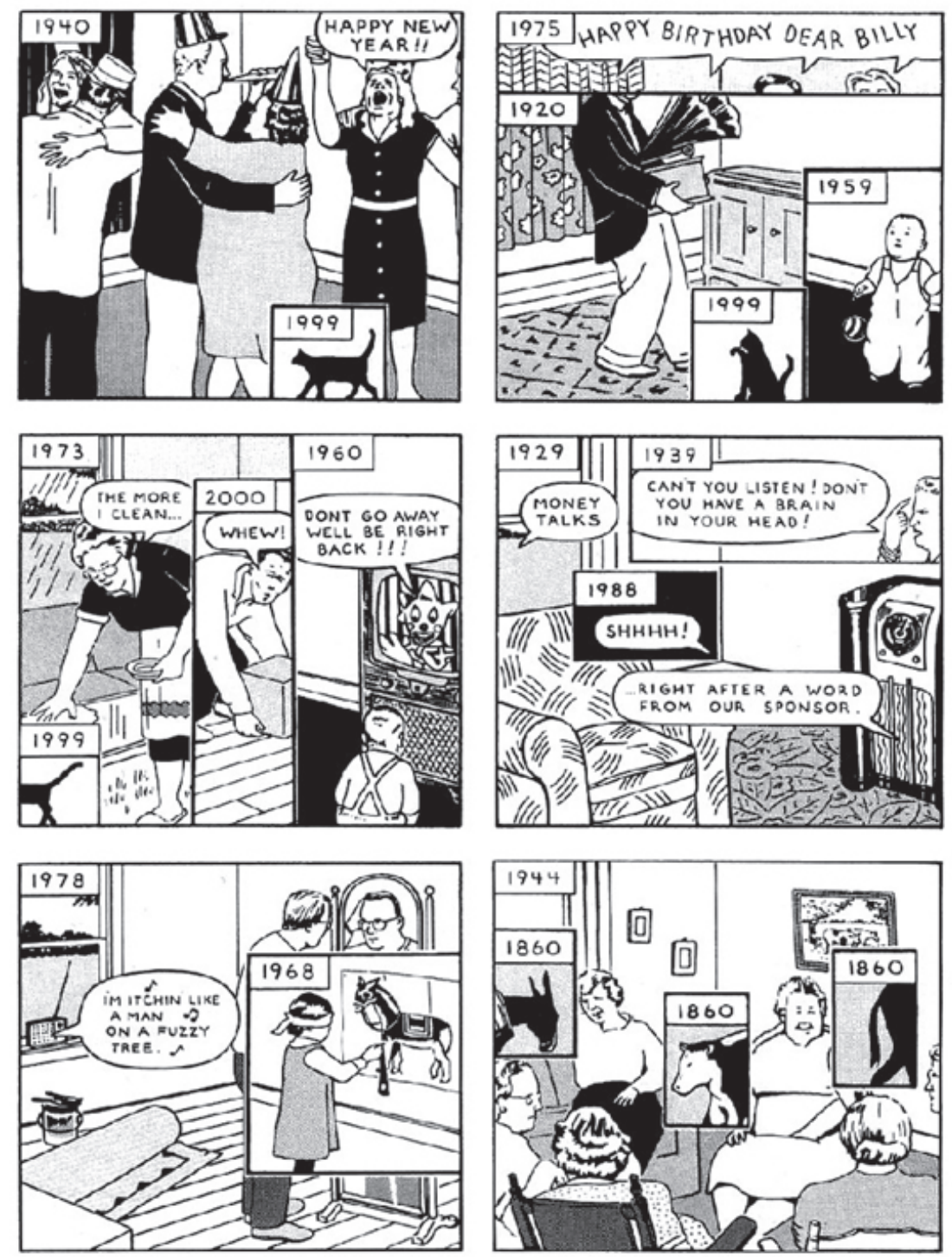

FIG. 9. McGuire, R. Here, en Raw Comics n. ${ }^{\circ} 2$

(1989). 


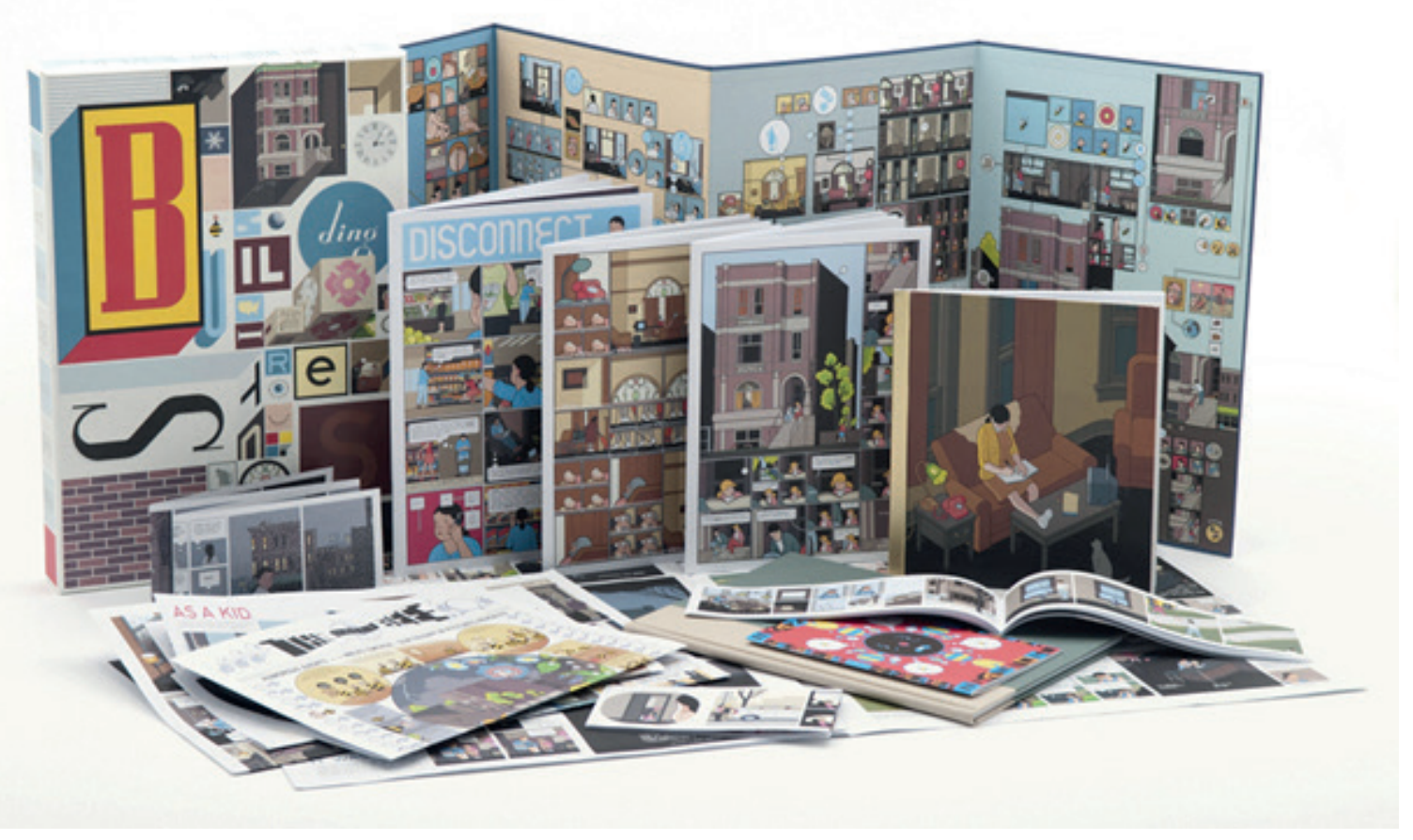

FIG. 10. Ware, C. Bulding Stories. Phanteon Graphic Novels, 2012. 